spreading at the beginning of therapy. Moreover, Kobsa et al. [11] produced an electrospun nanofiber scaffold to treat the cutaneous wounds. They found that nanofiber PLA/PCL scaffolds can effectively control DNA delivery.

Electrospinning is a proper and easy method consisting of four main parameters: 1 . High voltage-power supply, 2. Spinneret, 3. collector, and 4. Micro-pomp (feeding system) $[12,13]$. Electrospun nanofiber has been widely employed in biomedical applications such as tissue engineering [14-17] and wound dressing [18-20]. Kyziol et al. [21] used the electrospinning method to produce sodium alginate nanofiber loaded with ciprofloxacin hydrochloride. In their study, using the biopolymer, and cross-linker, makes the scaffolds promising for different biomedical applications such as wound healing, and drug delivery system. Mohseni et al. [22], presented a porous wound dressing from polycaprolactone (PCL) and PVA nanofibers with flexibility, and hydrophilicity that obtain requisite physical properties for wound dressing. They indicated that coating fibronectin was stated as a proper method to enhance the biocompatibility of scaffold incorporated with silver sulfadiazine (SSD). Furthermore, Mohseni et al. [23] considered the antimicrobial wound dressing loaded with silver sulfadiazine (SSD) or AgNPs and evaluate their efficiency in the process of wound healing. Based on their results, PCL/PVA nanofibers conjugated with AgNPs are promising wound dressing for the full-thickness wound. Jatoi et al. [24] developed a novel antibacterial wound dressing using PVA nanofiber. Their experimental results confirmed good bactericidal and suggest a sustained antibacterial wound dressing biomaterial. Also, several researches have been done to investigate the blood clotting ability of dressings. Wiegand et al. [25] carried out different examinations for evaluating the efficacy of cotton gauze (Gazin ${ }^{R}$, Lohmann \& Rauscher, Germany), collagen SC (Suprasorb ${ }^{R}$ C, Lohmann \& Rauscher, Germany) and collagen PC (PuracolTM, Medline Industries Inc., USA), and oxidized regenerated cellulose (Tabotamp ${ }^{R}$, Johnson \& Johnson, USA) to improve blood clotting, coagulation, and platelet activation. Gu et al. [26] produced pure chitosan nanofiber utilizing the electrospinning technique. Their results showed that the sonicated chitosan nanofiber mat can act as a hemostatic wound dressing.

By investigating the promotion of community standards, there is a need for products that can simultaneously act in several operations together. Also, this is evident in wound dressing. In this regard, few researches have been carried out on wound dressing that can perform both as a wound dressing and as a blood coagulant. In this study, an attempt was made to fabricate the wound dressings using the electrospinning method blending TXA with PVA for considering blood coagulation properties. Furthermore, the blending of CTX with PVA was done to investigate antibacterial properties. The effects of drug concentration changes on these properties were also studied in detail.

\section{Experimental section}

\subsection{Loaded PVA nanofibers with drug}

Poly (vinyl alcohol) (PVA, Mw $=89,000$, Sigma-Aldrich, USA) solution was produced by dissolving $5 \% \mathrm{wt} / \mathrm{wt}$ PVA in distilled water for $4 \mathrm{~h}$ at $85^{\circ} \mathrm{C}$. Ceftriaxone (Sigma-Aldrich, USA) (MIC: 0.1, 1, $8 \mu \mathrm{g} / \mathrm{ml}$ ) and Tranexamic acid (Caspian tamin, Iran) $(10,20 \mathrm{mg} / \mathrm{ml})$ added to the polymer matrix directly and stirred for $2 \mathrm{~h}$ for loading drugs in PVA. Electrospinning was done in a voltage of $20 \mathrm{kv}, 12 \mathrm{~cm}$ from tip to collector, and feed rate of $1.2 \mathrm{ml} / \mathrm{h}$ and fabricated of nanofiber was collected on an aluminum foil.

\subsection{Characterization}

Morphology of electrospun nanofiber was investigated with scanning electron microscopy (FE-SEM, Sigma, Zeiss German (. The fiber diameter was captured using Image $J(N I H, U S A)$ software. The viscosity of polymer solutions was evaluated with Brookfield's viscometer DV-II + PRO at a temperature of $24^{\circ} \mathrm{C}$ at $100 \mathrm{rpm}$.

\subsection{Coagulation of blood}

The blood clotting test was implemented based on previous studies [27]. Hence, the dressings PVA, PVA/TXA $10 \mathrm{mg} / \mathrm{ml}$, PVA/TXA $20 \mathrm{mg} / \mathrm{ml}$ were cut to $1 \times 1 \mathrm{~cm}^{2}$ dimensions and placed in glass bottles. $0.1 \mathrm{ml}$ of human blood was mixed with anticoagulant agent acid-citrate-dextrose at a ratio of 9:1 added to each composite nanofiber mats and placed in a $25 \mathrm{ml}$ plastic Petri dish, followed by addition of $10 \mu \mathrm{L}$ of $0.2 \mathrm{M} \mathrm{CaCl}_{2}$ solutions for initiation of blood clotting and PVA mat was employed as a negative control. Then, they were incubated at $37^{\circ} \mathrm{C}$ for $10 \mathrm{~min}$. Also, $15 \mathrm{ml}$ of distilled water was added dropwise without disturbing the clot. Afterward, $10 \mathrm{ml}$ of solution was taken from the dishes and centrifuged at $1000 \mathrm{rpm}$ for $1 \mathrm{~min}$. The supernatant was collected for each sample and kept at $37{ }^{\circ} \mathrm{C}$ for $1 \mathrm{~h} .200 \mu \mathrm{l}$ of this solution was transferred to a 96-well plate. The optical density was tested at $540 \mathrm{~nm}$ with a plate reader (Dynex Technologies USA).

\subsection{Investigation of platelet activation}

To evaluate platelet activation for 3 dressings including PVA, PVA/TXA $10 \mathrm{mg} / \mathrm{ml}$, and PVA/TXA $20 \mathrm{mg} / \mathrm{ml}$ were cut to $1 \times 1 \mathrm{~cm}^{2}$ dimensions. Platelet Rich Plasma (PRP) was isolated from the blood by centrifugation of blood 
at $2500 \mathrm{rpm}$ for $5 \mathrm{~min} .100 \mu \mathrm{l}$ of PRP was poured onto the composite nanofiber mat and incubated at $37^{\circ} \mathrm{C}$ for $20 \mathrm{~min}$. Then, composite nanofiber mat was washed three times with PBS solution and fixed with $0.1 \%$ glutaraldehyde solution. The mat was dried and the SEM image was taken [27].

\subsection{Antibacterial activity}

First, the agar culture medium for the growth of bacteria was produced for examination. Escherichia coli (AATCC 11303) and Staphylococcus aureus (AATCC 25938) were employed for determining anti-bactericidal property. Microbial culture was prepared in growth enrichment broth for $24 \mathrm{~h}$ of incubation for obtaining a high concentration of test organisms. Therefore, bacterial suspensions with a concentration of $1.5 \times 10^{8} \mathrm{CFU} \mathrm{ml}{ }^{-1}$ were produced and added $10 \mu \mathrm{l}$ suspensions dilute of $S$. aureus and E. coli to dressing with $1 \times 1 \mathrm{~cm}^{2}$ dimension. Then, organism inoculated dressing is incubated for $24 \mathrm{~h}$ under the favorable condition of nutrient and temperature. Finally, the number of bacterial colonies culture media was counted, and by Eq. (1) the percentage of bacteria was decreased [28].

$R=100(B-A) / B$

where $\mathrm{R}$ is \% reduction, $\mathrm{A}$ denotes the number of bacteria recovered from the inoculated treated test specimen swatches in the jar incubated over desired contact period, $B$ represents the number of bacteria recovered from the inoculated treated test specimen swatches in the jar immediately after inoculation (at 0 contact time) [29].

\section{Results and discussion}

\subsection{Viscosity and morphology of electrospun mats}

SEM images were examined to investigate surface morphology of PVA, PVA/TXA, and PVA/CTX (Fig. 1). It was concluded that PVA nanofiber and PVA nanofiber loaded with TXA and CTX were fabricated uniformly and without the bead. Also, the addition of TXA and CTX to PVA did not change the morphology of nanofibers, but the diameter of nanofibers varied with changes in viscosity of the polymer solution [30]. Solution viscosity plays a major role in determining the size of fiber and morphology during polymer fiber spinning [31]. It was found that by adding CTX to the PVA polymer solution, the viscosity of polymer solution enhanced due to the size and structure of the CTX molecules, which lead to have more interaction with surrounding molecules. The other reason for increasing the viscosity was using CTX in powder form. It can be seen in Table 1, with the increase of CTX concentration, the viscosity raised, thereby increasing the diameter of nanofiber. The diameter of nanofiber loaded with CTX was higher than PVA nanofibers, this could be due to the drug entrapped within the polymeric chain of nanofibers resulting in the increment of fiber diameter [32]. Also, with the increase of TXA drug, the viscosity of PVA polymer solution had decreased because of the disruption in chain involvement of polymer chains. This reduction in the viscosity of polymer solution actually reduces the viscoelastic force in the electrospinning process. Another reason for the reduction of viscosity is using TXA in the form of a solution. The average diameter of the fabricated nanofiber reduced with decreasing viscosity [33].

\subsection{The ability of blood coagulation}

The hemostatic property of TXA mainly relates to its ability for inhibiting conversion of plasminogen to plasmin. Thus, it prevents excessive blood loss in hyperfibrinolytic conditions. Plasmin breaks down fibrinogen and a series of proteins which are involved in coagulation [34]. A general review of blood coagulation was carried out to analyze the potential of scaffold nanofibrous coagulation. After adding the blood, the nanofibrous coating was completely covered with blood. After 10 min of incubation, the dressings indicated complete blood coagulation. The red blood cells trapped in the clot were hemolyzed with water. The absorbance of the hemoglobin solution was obtained $540 \mathrm{~nm}$. The amount of absorption above the hemoglobin solution shows a slower rate of blood coagulation [35]. From the measurements of hemoglobin absorption in $540 \mathrm{~nm}$, as shown in Fig. 2, it was found that the PVA/ TXA (20 mg/ml) sample had lower absorption values than the PVA/TXA $(10 \mathrm{mg} / \mathrm{ml})$. Also, PVA/TXA $(20 \mathrm{mg} / \mathrm{ml})$ and PVA/TXA (10 mg/ml) had higher blood coagulation ability than PVA (negative control). As illustrated in Fig. 3, the clots formed on PVA/TXA $(20 \mathrm{mg} / \mathrm{ml})$ were larger than the clots formed on PVA/TXA $(10 \mathrm{mg} / \mathrm{ml})$, and no clots were formed on pure PVA [36].

\subsection{Platelet activation}

SEM images depict that pure PVA activated platelets. However, compared to active platelets across the surface of nanofibers, PVA 5\%-XA (10 mg/ml) and PVA 5\%-XA $(20 \mathrm{mg} / \mathrm{ml}$ ) have been less widely spread (Fig. 4). It was observed that TXA inhibited plasmin catalytic activity and not platelet aggregation because platelet aggregation increased with increasing TXA [37]. A remarkable number of adhered red blood cells, as well as thrombus formation, were observed [38]. SEM images also showed that more platelet activation was captured in PVA 5\%-TXA $(20 \mathrm{mg} /$ 
Fig. 1 Images of electron microscopy of nanofiber loaded with the drug a PVA $5 \%$, b PVA 5\%-TXA $(10 \mathrm{mg} / \mathrm{ml})$, c PVA $5 \%-T X A(20 \mathrm{mg} / \mathrm{ml})$, d PVA $5 \%$-CTX $(0.1 \mu \mathrm{g} / \mathrm{ml})$, e PVA $5 \%-C T X(1 \mu \mathrm{g} / \mathrm{ml})$, f PVA5\%CTX $(8 \mu \mathrm{g} / \mathrm{ml})$
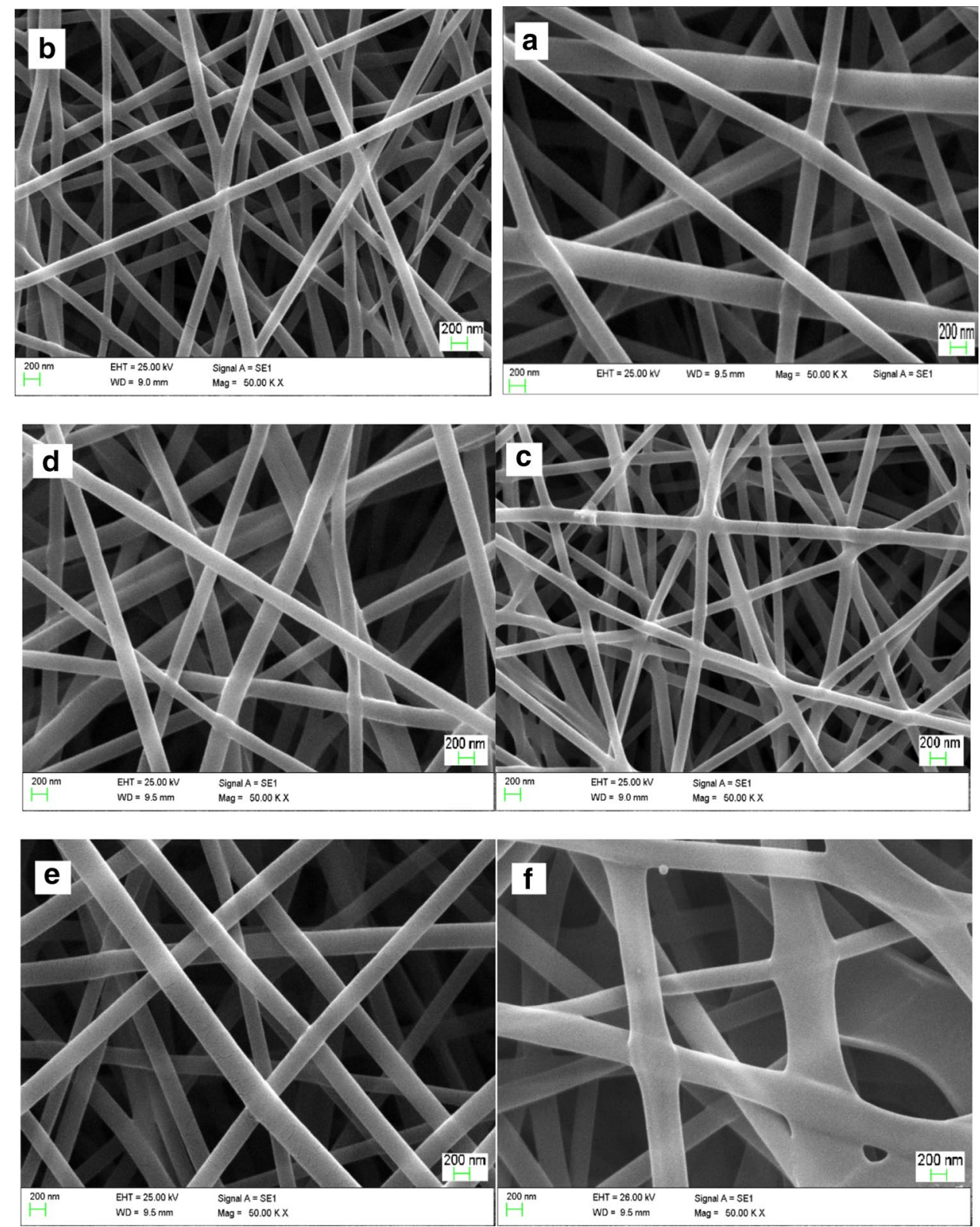

Table 1 The effect of viscosity of polymer solution

\begin{tabular}{lll}
\hline Nanofiber diameter & Viscosity cp & Polymeric solution components \\
\hline $250 \pm 84$ & 384 & PVA 5\% \\
$124 \pm 55$ & 234 & PVA 5\%-TXA $(10 \mathrm{mg} / \mathrm{ml})$ \\
$110 \pm 44$ & 193 & PVA 5\%-TXA $(20 \mathrm{mg} / \mathrm{ml})$ \\
$258 \pm 93$ & 396 & PVA 5\%-CTX $(0.1 \mu \mathrm{g} / \mathrm{ml})$ \\
$273 \pm 99$ & 416 & PVA 5\%-CTX $(1 \mu \mathrm{g} / \mathrm{ml})$ \\
$379 \pm 225$ & 476 & PVA 5\%-CTX $(8 \mu \mathrm{g} / \mathrm{ml})$ \\
\hline
\end{tabular}

$\mathrm{ml}$ ) nanofibers. Uniform distribution of platelets along the nanofibers indicated complete adhesion of the platelets and thus the ability to coagulate blood [39].

\subsection{Antimicrobial test}

Open wounds are very sensitive to infectious bacteria. Once the wound becomes infected, it needs additional treatments which are painful and caused to delay the healing. Using antimicrobial materials in wound dressings provides enhancement of protection [40]. Since ceftriaxone is used in the composition of nanofiber, ceftriaxone is a third-generation cephalosporin. Therefore, the nanofiber leads to inhibition of cell wall synthesis and inhibition of peptidoglycan cross-linking. They also play a role in activating bacterial cell autolysins that may be involved in bacterial cell lysis. The antibacterial property of nanofiber was evaluated by counting the 


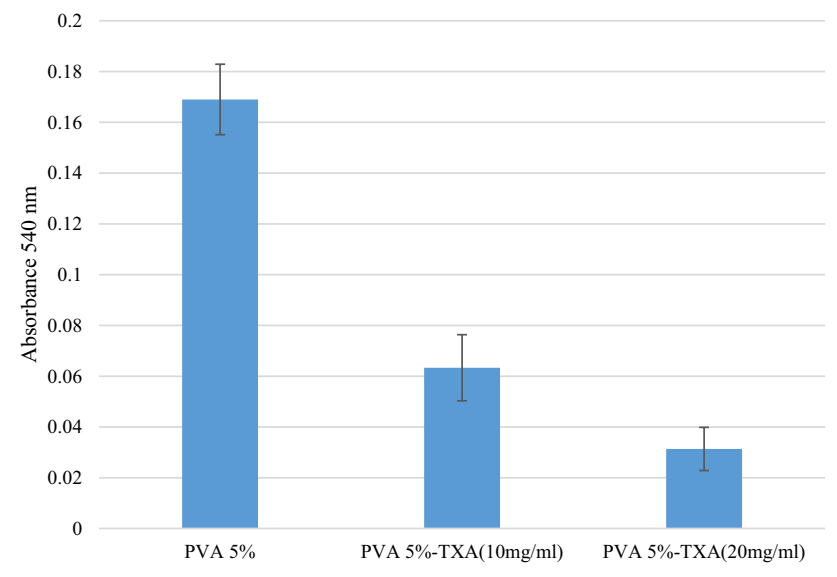

Fig. 2 Absorption value of hemoglobin solution

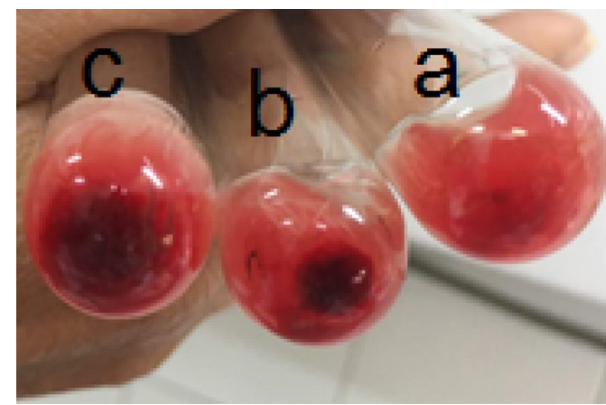

Fig. 3 Blood clotting coagulation a PVA 5\%, b PVA 5\%-TXA (10 mg/ $\mathrm{ml})$, c PVA $5 \%-T X A(20 \mathrm{mg} / \mathrm{ml})$ colony formation on the plates and calculating the percent inhibition using the formula $R=100(B-A) / B$. The results are presented in Fig. 5 to obtain the appropriate percentage of CTX antibiotics against Gram-negative (E. coli) and Gram-positive (S. aureus) bacteria. As it can be seen, as the antibiotic concentration increased, the number of colonies decreased and the percentage of inhibition increased. As the antibiotic concentration reached $8 \mu \mathrm{g} / \mathrm{ml}$, no colonies were observed on both Gram-negative and Gram-positive bacteria plates [41]. It was also observed in $0.1,1 \mu \mathrm{g} / \mathrm{ml}$ MIC: the rate of inhibition against $E$. coli gram-negative bacteria is higher than S. aureus gram-positive bacteria [42]. Therefore, it was concluded that the best value of using CTX for dressing was MIC: $8 \mu \mathrm{g} / \mathrm{ml}$ with more antimicrobial activity.

\section{Conclusion}

In this study, PVA nanofibers loaded with different drugs (TXA, CTX) were prepared using electrospinning process. SEM images revealed that PVA/TXA, PVA/CTX nanofibers were fabricated uniformly and without beads. In antibacterial analysis, PVA/CTX nanofibers were found to be good antibacterial properties against Gram-negative bacteria E. coli and the Gram-positive bacteria (S. aureus) because ceftriaxone is an antibiotic with a cell wall inhibition mechanism. PVA nanofibers loaded with TXA have good blood coagulation ability, and since TXA prevents the conversion of plasminogen to plasmin, it does not reduce platelet aggregation. Overall, PVA/CTX $8 \mu \mathrm{g} / \mathrm{ml}$, PVA/TXA $20 \mathrm{mg} / \mathrm{ml}$ nanofibers can be employed as a distinguished product for wound dressing application because they have great potential than all other concentrations of CTX and TXA.
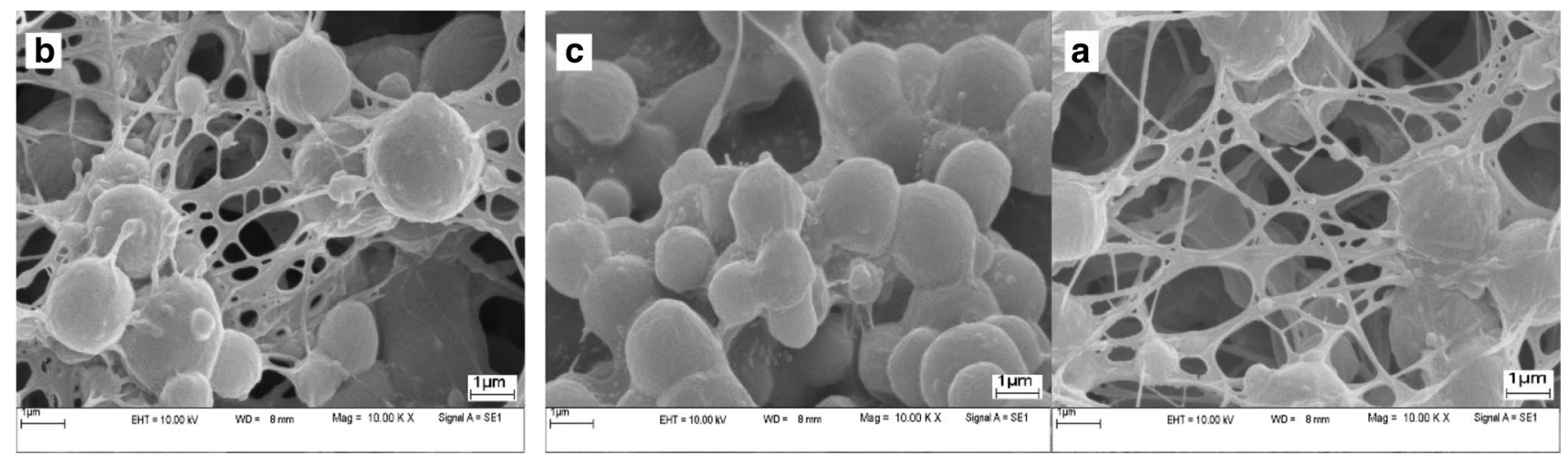

Fig. 4 SEM images of platelet activation a PVA 5\%, b PVA 5\%-TXA $(10 \mathrm{mg} / \mathrm{ml})$, c PVA 5\%-TXA (20 mg/ml) 


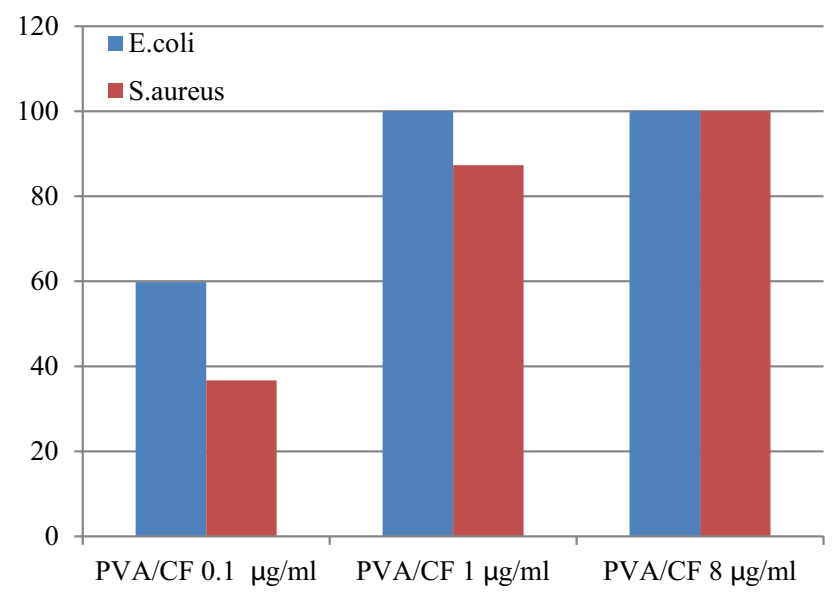

Fig. 5 Inhibitory percentage of PVA/CTX scaffold with MIC: 0.1, 1 and $8 \mu \mathrm{g} / \mathrm{ml}$ MIC: against Gram-negative E. coli and S. aureus Grampositive

\section{Compliance with ethical standards}

Conflict of interest The authors declare that they have no conflict of interest.

\section{References}

1. Gizaw M, Thompson J, Faglie A, Lee SY, Neuenschwander P, Chou SF (2018) Electrospun fibers as a dressing material for drug and biological agent delivery in wound healing applications. Bioengineering 5(1):9-20

2. Dong $Y$, Zheng $Y$, Zhang $K$, Yao Y, Wang L, Li X, Yu J, Ding B (2020) Electrospun nanofibrous materials for wound healing. Adv Fiber Mater 2(2):1-16

3. Mwiiri FK, Daniels R (2020) Electrospun nanofibers for biomedical applications. In: Delivery of drugs. Elsevier, pp 53-74

4. Fatahian R, Mirjalili M, Khajavi R, Rahimi M K, Nasirizadeh N (2018) Recent studies on nanofibers based wound-dressing materials: A review. 7th International Conference on Engineering \& Applied Sciences. France: 1-12

5. Arunkumar RP (2017) A review on hemostatic wound dressings. IJARIIE 3(3):3908-3913

6. Yin M, Wang Y, Zhang Y, Ren X, Qiu Y, Huang TS (2020) Novel quaternarized $\mathrm{N}$-halamine chitosan and PVA nanofibrous membranes as hemostatic materials with excellent antibacterial properties. Carbohydr Polym 232:115823

7. Xue H, Hu L, Xiong Y, Zhu X, Wei C, Cao F, Liu Y (2019) Quaternized chitosan-Matrigel-polyacrylamide hydrogels as wound dressing for wound repair and regeneration. Carbohydr Polym 226:115302

8. Muzzarelli RA, Guerrieri M, Goteri G, Muzzarelli C, Armeni T, Ghiselli R, Cornelissen M (2005) The biocompatibility of dibutyryl chitin in the context of wound dressings. Biomaterials 26(29):5844-5854

9. Mi FL, Shyu SS, Wu YB, Lee ST, Shyong JY, Huang RN (2001) Fabrication and characterization of a sponge-like asymmetric chitosan membrane as a wound dressing. Biomaterials 22(2):165-173
10. De Cicco F, Porta A, Sansone F, Aquino RP, Del Gaudio P (2014) Nanospray technology for an in situ gelling nanoparticulate powder as a wound dressing. Int J Pharm 473(1-2):30-37

11. Kobsa S, Kristofik NJ, Sawyer AJ, Bothwell AL, Kyriakides TR, Saltzman WM (2013) An electrospun scaffold integrating nucleic acid delivery for treatment of full-thickness wounds. Biomaterials 34(15):3891-3901

12. Liang D, Hsiao BS, Chu B (2007) Functional electrospun nanofibrous scaffolds for biomedical applications. Adv Drug Deliv Rev 59(14):1392-1412

13. Huang ZM, Zhang YZ, Kotaki M, Ramakrishna S (2003) A review on polymer nanofibers by electrospinning and their applications in nanocomposites. Compos Sci Technol 63(15):2223-2253

14. Kalantari $K$, Afifi AM, Jahangirian $H$, Webster TJ (2019) Biomedical applications of chitosan electrospun nanofibers as a green polymer-review. Carbohydr Polym 207:588-600

15. Abbasian V, Emadi R, Kharaziha M (2020) Biomimetic nylon 6-baghdadite nanocomposite scaffold for bone tissue engineering. Mater Sci Eng C 109:110549

16. Govindasamy K, Dahlan NA, Janarthanan P, Goh KL, Chai SP, Pasbakhsh P (2020) Electrospun chitosan/polyethylene-oxide (PEO)/halloysites (HAL) membranes for bone regeneration applications. Appl Clay Sci 190:105601

17. Subramanian A, Vu D, Larsen GF, Lin HY (2005) Preparation and evaluation of the electrospun chitosan/PEO fibers for potential applications in cartilage tissue engineering. J Biomater Sci Polym Ed 16(7):861-873

18. Ghaffari-Bohlouli $P$, Hamidzadeh F, Zahedi $P$, Shahrousvand $M$, Fallah-Darrehchi M (2020) Antibacterial nanofibers based on poly (I-lactide-co-d, I-lactide) and poly (vinyl alcohol) used in wound dressings potentially: a comparison between hybrid and blend properties. J Biomater Sci Polym Ed 31(2):219-243

19. Zhou Y, Yang D, Chen X, Xu Q, Lu F, Nie J (2008) Electrospun water-soluble carboxyethyl chitosan/poly (vinyl alcohol) nanofibrous membrane as potential wound dressing for skin regeneration. Biomacromolecules 9(1):349-354

20. Tang $Y$, Lan $X$, Liang $C$, Zhong Z, Xie R, Zhou Y, Miao X, Wang H, Wang W (2019) Honey loaded alginate/PVA nanofibrous membrane as potential bioactive wound dressing. Carbohydr Polym 219:113-120

21. Kyzioł A, Michna J, Moreno I, Gamez E, Irusta S (2017) Preparation and characterization of electrospun alginate nanofibers loaded with ciprofloxacin hydrochloride. Eur Polym J 96:350-360

22. Mohseni M, Shamloo A, Aghababaei Z, Vossoughi M, Moravvej H (2016) Antimicrobial wound dressing containing silver sulfadiazine with high biocompatibility: in vitro study. Artif Organs 40(8):765-773

23. Mohseni M, Shamloo A, Aghababaie Z, Afjoul H, Abdi S, Moravvej $\mathrm{H}$, Vossoughi $\mathrm{M}$ (2019) A comparative study of wound dressings loaded with silver sulfadiazine and silver nanoparticles: in vitro and in vivo evaluation. Int J Pharm 564:350-358

24. Jatoi AW, Ogasawara H, Kim IS, Ni QQ (2019) PVA nanofiber based three phase wound dressings for sustained wound healing applications. Mater Lett 241:168-171

25. Wiegand C, Abel M, Hipler UC, Elsner P, Zieger M, Kurz J, Stoppelkamp S (2019) Hemostatic wound dressings: predicting their effects by in vitro tests. J Biomater Appl 33(9):1285-1297

26. Gu BK, Park SJ, Kim MS, Kang CM, Kim JI, Kim CH (2013) Fabrication of sonicated chitosan nanofiber mat with enlarged porosity for use as hemostatic materials. Carbohydr Polym 97(1):65-73

27. Ong SY, Wu J, Moochhala SM, Tan MH, Lu J (2008) Development of a chitosan-based wound dressing with improved hemostatic and antimicrobial properties. Biomaterials 29(32):4323-4332

28. Souriyan-Reyhani Pour H, Khajavi R, Yazdanshenas ME, Zahedi P, Mirjalili M (2018) Cellulose acetate/poly (vinyl alcohol) hybrid 
fibrous mat containing tetracycline hydrochloride and phenytoin sodium: morphology, drug release, antibacterial, and cell culture studies. J Bioactive Compatible Polym 33(6):597-611

29. Yurudu NS, Erdem AK, Yürüdü NŞ (2008) The evaluation of antibacterial activity of fabrics impregnated with dimethyltetradecyl (3-(trimethoxysilyl) propyl) ammonium chloride. Eur J Biol 67(2):115-122

30. Khan MQ, Kharaghani D, Shahzad A, Saito Y, Yamamoto T, Ogasawara H, Kim IS (2019) Fabrication of antibacterial electrospun cellulose acetate/silver-sulfadiazine nanofibers composites for wound dressings applications. Polym Testing 74:39-44

31. Akhgari A, Heshmati Z, Makhmalzadeh BS (2013) Indomethacin electrospun nanofibers for colonic drug delivery: preparation and characterization. Adv Pharm Bull 3(1):85

32. Kataria K, Gupta A, Rath G, Mathur RB, Dhakate SR (2014) In vivo wound healing performance of drug loaded electrospun composite nanofibers transdermal patch. Int J Pharm 469(1):102-110

33. Munteanu BS, Aytac Z, Pricope GM, Uyar T, Vasile C (2014) Polylactic acid (PLA)/Silver-NP/VitaminE bionanocomposite electrospun nanofibers with antibacterial and antioxidant activity. $J$ Nanopart Res 16(10):2643

34. Sarda S, Errassifi F, Marsan O, Geffre A, Trumel C, Drouet C (2016) Adsorption of tranexamic acid on hydroxyapatite: toward the development of biomaterials with local hemostatic activity. Mater Sci Eng C 66:1-7

35. Kang PL, Chang SJ, Manousakas I, Lee CW, Yao CH, Lin FH, Kuo SM (2011) Development and assessment of hemostasis chitosan dressings. Carbohydr Polym 85(3):565-570

36. Liao N, Unnithan AR, Joshi MK, Tiwari AP, Hong ST, Park CH, Kim CS (2015) Electrospun bioactive poly ( $\varepsilon$-caprolactone)-cellulose acetate-dextran antibacterial composite mats for wound dressing applications. Colloids Surf A 469:194-201

37. Soslau G, Horrow J, Brodsky I (1991) Effect of tranexamic acid on platelet ADP during extracorporeal circulation. Am J Hematol 38(2):113-119

38. Spasova M, Manolova N, Paneva $D$, Mincheva $R$, Dubois $P$, Rashkov I, Danchev D (2010) Polylactide stereocomplex-based electrospun materials possessing surface with antibacterial and hemostatic properties. Biomacromol 11(1):151-159

39. Unnithan AR, Gnanasekaran G, Sathishkumar Y, Lee YS, Kim CS (2014) Electrospun antibacterial polyurethane-cellulose acetate-zein composite mats for wound dressing. Carbohydr Polym 102:884-892

40. Liu R, Xu X, Zhuang X, Cheng B (2014) Solution blowing of chitosan/PVA hydrogel nanofiber mats. Carbohydr Polym 101:1116-1121

41. Zhao R, Li X, Sun B, Zhang Y, Zhang D, Tang Z, Chen X, Wang C (2014) Electrospun chitosan/sericin composite nanofibers with antibacterial property as potential wound dressings. Int J Biol Macromol 68:92-97

42. Fatahian $\mathrm{R}$, Mirjalili $\mathrm{M}$, Khajavi $\mathrm{R}$, Rahimi MK, Nasirizadeh $\mathrm{N}$ (2020) A novel hemostat and antibacterial nanofibrous scaffold based on poly (vinyl alcohol)/poly (lactic acid). J Bioact Compat Polym 35(3):189-202

Publisher's Note Springer Nature remains neutral with regard to jurisdictional claims in published maps and institutional affiliations. 